\title{
A ASSISTÊNCIA SOCIAL NO PROCESSO DE RESTAURAÇÃO DA DOMINAÇÃO BURGUESA NO BRASIL
}

\author{
Adilson Aquino Silveira Júnior \\ Universidade Federal de Pernambuco (UFPE) \\ Simone Souza Leite \\ Autarquia Educacional de Serra Talhada (AESET)
}

\section{A ASSISTÊNCIA SOCIAL NO PROCESSO DE RESTAURAÇÃO DA DOMINAÇÃO BURGUESA NO BRASIL}

Resumo: Este texto analisa as mediações (institucionais, ideopolíticas e socioeconômicas) acionadas através do campo da assistência social que contribuem para a consolidação da hegemonia burguesa no Brasil. Para tanto, realiza uma revisão bibliográfica abrangendo as produções críticas que tratam dessa política social, além de incorporar elaborações teóricas sobre as disputas hegemônicas entre as classes na contemporaneidade. 0 artigo aborda 0 destaque assumido pelos programas de transferência de renda, articulado ao conjunto de conceitos e concepções ideopolíticos e práticas político-pedagógicas desenvolvidas através da assistência social enquanto um conjunto articulado de estratégias acionadas para a consolidação da hegemonia burguesa no Brasil. Desse modo, identifica que a reconfiguração das diversas dimensões dessa política social pelas classes dominantes orienta-se para processos de passivização das classes subalternas.

Palavras-chave: Assistência Social, hegemonia, programas de transferência de renda, estratégia ideopolíticas.

\section{THE SOCIAL ASSISTANCE IN THE RESTORATION PROCESS OF BOURGEOIS DOMINATION IN BRAZIL}

Abstract: This paper examines the mediations (institutional, political-ideological and socioeconomic) activated through the field of social assistance that contributes to the consolidation of bourgeois hegemony in Brazil. The study presents a literature review covering the critical productions that address this social policy, besides incorporating theoretical elaborations about the currently disputes between the hegemonic classes. The article discusses the emphasis given to the income transfer programs, articulated to the politicalideological concepts and conceptions and political-pedagogical practices developed by social assistance as a coordinated set of strategies used for the consolidation of bourgeois hegemony in Brazil. In this way, identifies that the reconfiguration of the various dimensions of social policy by the ruling class is oriented towards processes of passivization the subaltern classes.

Key words: Social Assistance, hegemony, income transfer programs, political-ideological strategy. 


\section{INTRODUÇÃO}

A Assistência Social tem se constituído um espaço de investigação privilegiado no âmbito do Serviço Sociall'. As produções na área constituem referência para pesquisadores e estudantes em diversos campos do conhecimento, incorporando um leque bastante abrangente de enfoques sobre essa política social. Não obstante, ainda evidenciamos abordagens limitadas a pseudoconcreticidade do mundo fenomênico (KOSIK, 1976), procedendo à fragmentação da realidade social e fomentando 0 imediatismo nas análises, associado aos enfoques limitados às esferas superestruturais e institucionais. Encontramos também trabalhos que focalizam os segmentos alvos das ações socioassistenciais em si mesmos, isolando o seu tratamento analítico das relações sociais que os constituem. A fragilidade da apropriação da realidade estudada em sua relação com o movimento concreto, e historicamente determinado, das disputas hegemônicas entre as classes, proporciona um obscurecimento da conflitualidade social e do caráter antagonisticamente estruturado do sistema imperante ${ }^{2}$. Consideramos que as investigações existentes - mesmo aquelas circunscritas aos instrumentos de gestão, as estratégias de operacionalização e as formas de organização dos programas, projetos, serviços e benefícios socioassistenciais - devem ser fortalecidas no sentido de desenvolver a análise da assistência social considerando-a no interior do movimento de restauração das bases de domínio do capital em crise. Portanto, devem articular-se a tentativa de apreendê-la - a partir da perspectiva da totalidade concreta e da historicidade - na dinâmica das lutas hegemônicas entre as classes desencadeadas na esteira da crise orgânica do capitalismo tardio (MANDEL, 1985) no Brasil, de natureza periférica e subordinada.

Neste texto, apresentaremos um debate introdutório, a partir de uma abordagem críticodialética, sobre as mediações (institucionais, ideológicas e socioeconômicas), acionadas no campo da assistência social, que contribuem para a consolidação da hegemonia burguesa no Brasil. Tais mediações constituem-se através da ação dos aparelhos de hegemonia, da reorganização dasformas de vida estatal e da atuação dos intelectuais orgânicos das forças sociais em presença. A investigação desenvolvida possui o pressuposto de que a inserção da assistência no campo dos direitos sociais não significa sua imunização em face da possibilidade de capitulação pela hegemonia dominante no âmbito da reprodução social - orientada para processos de passivização das classes subalternas - ou seja, da contínua repolitização dessa política social pelas classes dominantes (MOTA, 2011).

Para a construção dessa análise, realizamos uma revisão bibliográfica, incorporando algumas abordagens no âmbito da tradição marxista, que buscam apreender as formas de dominação burguesa próprias do capitalismo contemporâneo, além daquelas que particularizam a formação brasileira. Também buscamos abranger a literatura crítica, no campo da assistência social, que fornece um panorama dessa Política em suas diferentes dimensões na conjuntura atual. Este texto é resultado da sistematização de parte dos estudos e pesquisas desenvolvidos pelos autores, no âmbito do Mestrado em Serviço Social, destinados à apreensão das transformações recentes operadas pela assistência social no Brasil, suas tendências histórico-concretas e suas implicações em termos das disputas hegemônicas das classes na formação social periférica e dependente.

\section{CRISE ORGÂNICA E RESTAURAÇÃO DO} CAPITAL: fundamentos para uma análise da assistência social no Brasil

As determinações históricas eos complexos causais mais gerais que condicionam a configuração das lutas hegemônicas contemporâneas podem ser demarcados - sem grandes prejuízos para análise - a partir das transformações societárias ocorridas no último quartel do século $X X$, quando o processo de acumulação do capital entra no que Mandel (1985) qualificou de onda longa com tonalidade de 
estagnação, configurando um contexto identificado pela redução das taxas de lucro e a queda do crescimento econômico mundial. É bastante fecundo o procedimento de Mészáros (2009) ao tratar essa como uma crise de dominação em geral do sistema do capital. A novidade histórica da crise estrutural desse modo de controle sociometabólico consiste, para esse autor, em quatro características principais: 1) sua natureza é global, não limitada a uma esfera pontual da estrutura socioeconômica, e abrange a máquina capitalista em seu conjunto; 2) seu alcance é concretamente mundial, refletindo em todas as nações imperialistas do planeta; 3) sua escala de tempo é extensa e contínua, em lugar de limitada e cíclica, caracterizada por uma fase de recessão que não vislumbra qualquer saída possível a curto ou longo prazo; 4) e seu modo de desdobramento é rastejante, ou seja, é lento e gradual, sem, no entanto, dispensar possíveis convulsões mais veementes $\mathrm{e}$ violentas.

Essa crise de dominação em geral incide sobre a totalidade da reprodução social fundada no metabolismo do capital em sua fase tardia: de uma parte, compromete a acumulação de capital mediada pela produção fordista, exigindo a reestruturação das unidades produtivas através das estratégias de acumulação flexível (ALVES, 2007; 2011; ANTUNES, 2007; HARVEY, 1993); de outra parte, afeta as mediações políticas, ideológicas e institucionais que se consolidaram, sobretudo, através dos sistemas de seguridade social de caráter mais universal nos países capitalistas centrais ${ }^{3}$, cujo corolário é a hegemonia do projeto neoliberal, privatizando e restringindo as políticas sociais (BEHRING, 2009; BOSCHETTI; BEHRING, 2007; NETTO, 1995). Essas determinações articulam-se à hipertrofia das relações financeiras (financeirização), que passam a constituir um campo prioritário da acumulação. As novas modalidades de acumulação estabelecemse nos marcos de uma inteira mundialização dos circuitos do capital, que, por sua vez, apresenta-se, de forma intensificada, concentrado e centralizado. Aprofunda-se, na mesma medida, a centralização do poder político nas mãos da burguesia monopolista, particularmente ligada ao capital financeiro (ALVES, 1999; DURIGUETTO, 2007; NETTO, 2004b).

A crise contemporânea de dominação possui, portanto, as características - ponderando as particularidades históricas de seu caráter estrutural - daquilo que Gramsci (2011) qualificou de crise orgânica ou crise de hegemonia, que afeta o conjunto das relações de forças de um bloco histórico. Para Ruy Braga (1996), a crise orgânica evidencia períodos históricos em que ocorreria um determinado amadurecimento consciente do caráter irreconciliável e insuperável - dentro da lógica de reprodução ampliada do capital - das contradições classistas, articulado ao não-esgotamento das possibilidades de luta e desdobramentos estratégicos da estrutura social dominante, o que inauguraria um renovado período de disputas e embates entre as classes e racionalidades, onde as tarefas postas são próprias das novas condições sociais e políticas. 0 referido autor acrescenta que a historicidade da crise contemporânea - para além dos elementos mencionados acima - materializa-se, ainda, na crise capitalista agregada à crise/colapso do chamado socialismo rea, desembocando na crise do projeto alternativo revolucionário e dos aparelhos de hegemonia da sociedade democrática (expressão da reação reformista aos processos emancipatórios de supressão das reações de produção capitalista).

Nesse sentido, temos uma relação importante - desenvolvida nos escritos carcerários de Gramsci - a ser considerada entre crise orgânica, revolução passiva e guerra de posição. A revolução passiva remete às formas de vida implícitas, e suas relações, que ainda podem ser desenvolvidas para a manutenção do domínio de classe burguês no contexto de crise orgânica - aqui as classes dominantes se utilizam do sistema de fortalezas e casamatas (a guerra de posição) possíveis na vida estatal (BRAGA, 1996). Essa relação diz respeito à capacidade historicamente determinada do sistema do capital de obsorver/dissipar/desconcentrar e desarmar, suas perturbações e disfunções antagônicas 
(MÉSZÁROS, 2009) através de seus mecanismos de controle e das inovações sociometabólicas de caráter produtivo e ideopolítico. A natureza estrutural da crise atual se expressa precisamente no caráter problemático desses deslocamentos, que passam a tornar cumulativos os limites e contradições relativos, em lugar de resolvê-los (MÉSZÁROS, 2009). Em nossa análise, consideramos que as mediações (socioeconômicas e ideopolíticas), apresentadas através da assistência social no Brasil, constituem atualmente algumas das fortalezas e casamatas utilizadas no processo hegemônico para restauração das bases de domínio tardo-burguês.

Como resultado da crise do capital, constitui-se um movimento de restauração de suas bases de domínio, que envolve estratégias de passivização, com expressões nos plano ideopolítico (neoliberalismo) e das forças produtivas (reestruturação produtiva) (BRAGA, 1996). Essa ofensiva enfrenta o desafio de fornecer respostas - através da reorganização da vida estatal - ao fenômeno dramático do desemprego crônico (MÉSZÁROS, 2009) proporcionado pela organização da produção reestruturada e pela recomposição da superpopulação relativa (questão essa fundamental para compreendermos o papel desempenhado pela assistência social atualmente ${ }^{4}$ ). As estratégias de passivização incorporam as inovações sociometabólicas representadas pela pletora de valores-fetiche, expectativas e utopias de mercado (ALVES, 2011) - associadas à reatualização dos mais mistificadores empreendimentos ideopolíticos -, que buscam realizar uma reforma intelectual e moral com vistas a adequar a consciência das classes à pratica social exigida pela dinâmica restauracionista impregnada nas diversas esferas do ser social capitalista.

A tarefa histórica da dinâmica restauracionista consiste na supressão de toda e qualquer iniciativa hegemônica por parte das classes subalternas objetivando superar as relações de produção dominantes - ou mesmo o desenvolvimento de iniciativas de resistência às mesmas - (re)conduzindo estas classes ao terreno das lutas econômico-corporativas (GRAMSCl, 2007). O recurso à estratégia transformista também constitui um elemento fundamental nesse processo, porquanto se refere à absorção moderadora dos elementos ativos, surgidos dos grupos sociais antagonistas, pelo movimento hegemônico das classes dominantes.

O Brasil da era da servidão financeira evidencia um movimento hegemônico-burguês fortalecido pelas forças políticas petistas, que confluem para 0 atendimento dos interesses das classes dominantes ${ }^{5}$. Esquematicamente, indicamos algumas direções assumidas pela supremacia de classe imperante: a absorção transformista das forças sociais antagônicas no aparato do Estado, passivizando as organizações operárias e os movimentos sociais; a restrição das práticas políticas democráticas aos marcos institucionais; a transfiguração da luta contra a miséria e a desigualdade em um problema de gestão das políticas públicas; a instrumentalização da pobreza, através de sua transformação em questão administrativa; a gestão burocrática (e mesmo coercitiva) dos conflitos sociais; os esforços de garantia do superávit primário destinado para o cumprimento das dívidas com o capital financeiro, correspondendo em cortes com gastos sociais diversos; o reforço das políticas focalizadas, estabelecidas através da lógica da rentabilidade do mercado; a forte ênfase aos programas de transferência de renda, em detrimento de um sistema de proteção social público orientado por critérios de universalização; a colonização dos aparelhos de hegemonia (públicos e privados) por concepções de mundo, valores e expectativas marcadas pela racionalidade integrista do capital; 0 acirramento de processos de individualização e psicologização das expressões da questão social (BRAGA, 2010; COUTINHO; 2010; OLIVEIRA, 2010). Abordaremos, em seguida, as particularidades da dinâmica restauracionista no âmbito específico da assistência social. 


\section{PARTICULARIDADES DA ASSISTÊNCIA SOCIAL NO PROCESSO DE DOMINAÇÃO BURGUESA NO BRASIL}

A institucionalização da assistência social como política pública, galgada a partir da aprovação da Constituição Federal de 1988 e da promulgação da Lei Orgânica da Assistência Social, $n^{\circ}$ 8.742, em 1993, inaugurou alternativas históricas para a constituição de condições mais favoráveis ao avanço de um projeto emancipatório das classes subalternas, inscrevendo a possibilidade de sua materialização através de patamares capazes de superar o marco assistencialista na qual se encontrava tradicionalmente aprisionada. A inserção da assistência no campo dos direitos sociais não inviabilizou, todavia, sua incorporação pelos processos de dominação que particularizam a supremacia tardo-burguesa. No contexto atual das relações de forças, o procedimento principal das classes dominantes consiste em transformar a assistência social num fetiche social (MOTA, 2011), colonizando-a por estratégias de passivização das classes subalternas.

No interior das disputas pela conquista da hegemonia, os direitos e políticas sociais tanto podem atuar no sentido subsidiar o desenvolvimento da consciência de classe dos trabalhadores e proporcionar melhores condições de vida para os mesmos; como podem, a partir da ofensiva das classes dominantes, assumir configurações restritivas e focalizadas, aprofundar os processos de alienação e passivização relativos à consolidação dos consensos requeridos para a reprodução ampliada das relações sociais capitalistas. No contexto atual de crise e restauração da dominação burguesa, as forças políticas imperantes tencionam fortemente seu direcionamento na perspectiva de atender as necessidades de acumulação e autoexpansão do capital. Segundo Netto (2006, p. 29, grifos do autor):

[...] apontar que demandas econômico-sociais e políticas imediatas de largas categorias de trabalhadores e da população podem ser contempladas pelo Estado burguês no capitalismo monopolista não significa que esta seja a sua inclinação "natural", nem que ocorra "normalmente" - o objetivo dos superlucros é a pedra de toque dos monopólios e do sistema de poder político de que eles se valem; entretanto, respostas positivas a demandas das classes subalternas podem ser oferecidas na medida exata em que elas podem ser refuncionalizadas para 0 interesse direto e/ou indireto da maximização dos lucros.

Considerando a relação entre a orientação macroeconômica das classes que exercem a hegemonia e a política social correspondente, o mesmo autor faz uma observação importante para compreendermos as mudanças no contexto brasileiro da última década - período marcado pela ascensão do Partido dos Trabalhadores e sua heterogênea composição (que congregou tanto setores da classe média e da burguesia brasileira, como intelectuais, movimentos sociais, forças sindicais etc.) no poder governamental:

Está claro que uma determinada orientação macroeconômica não comporta, deterministicamente, uma única matriz de política social: de fato, a orientação macroeconômica sinaliza um leque de alternativas, de desenhos possíveis de política social. Entretanto, o caráter amplo ou restrito desse leque é posto pela direção de classe concreta e específica que conforma a política macroeconômica. Isto significa que a política social do governo Lula guarda alternativas de implementação e redirecionamento e não tem, necessariamente, que ser uma simples reiteração daquela que marcou a era $\mathrm{FHC}$ - em especial no plano do gerenciamento, são possíveis alterações cujo significado não é pequeno; mas significa, igualmente, que os seus limites estruturais são os mesmos da era FHC (NETTO, 2004a, p. 17, grifos do autor). 
O compromisso assumido pelo governo Lula com o capital financeiro estabelece, para a conjuntura brasileira dos anos 2000, o mais significativo limite estrutural que as políticas sociais têm adquirido no âmbito do capitalismo contemporâneo: a impossibilidade de ampliação e universalização da proteção social a partir da base fundamental do direito ao trabalho. Na medida em que a ofensiva do capital, buscando intensificar a acumulação, amplia a superpopulação relativa e as formas precarizadas de trabalho, a política social assume uma configuração focalizada para 0 atendimento exclusivo dos contingentes humanos extremamente pobres. Com isso, Behring (2004, p. 12) afirma que, no lugar de um salto qualitativo, permaneceram as políticas focalizadas,

[... implementadas segundo a lógica do contador, a do mercado, dada a forte ênfase aos programas de transferência de renda, em detrimento da lógica do direito e da seguridade social universalizada.

Tais políticas constituem-se um eficiente instrumento que, longe de conter os efeitos mais perversos e destrutivos do capitalismo contemporâneo, passa a ser conformado para a passivização e 0 controle das camadas mais pauperizadas das classes subalternas (OLIVEIRA, 2008; SITCOVSKY, 2008).

Nesse cenário, a direção da seguridade social - à revelia do avanço jurídico-formal conquistado na transição democrática - reflete o seu ocaso. No âmbito da previdência foram empreendidas reformas que reforçaram a lógica do seguro e, por conseguinte, a dificuldade de acesso aos benefícios, ao tempo em que incentivou sua privatização, assegurando ao mercado a previdência privada como possibilidade de investimento rentável. A política de saúde sofreu uma tendência continuada de desinvestimento e desrespeito à proposta progressista universal e aos seus princípios de uma forma abrangente (MARQUES, 2010).
No que se refere ao investimento orçamentário da união na esfera da proteção social, a Coggiola (2009) conclui que, na vigência do governo petista, os recursos voltados aos direitos universais estabelecidos constitucionalmente sofreram um retrocesso relativo, ao contrário dos programas sociais localizados, sobremaneira, no âmbito da política de assistência social. Os dados de Boschetti (2009) reiteram essa perspectiva, assinalando que os investimentos na seguridade social evidenciam um crescimento de recursos na assistência social de $11 \%$ entre 2004 e 2007, e, no mesmo prazo, uma queda de $0,7 \%$ na saúde, $7,4 \%$ na educação, $5 \%$ na cultura e $44 \%$ na habitação e saneamento. No intervalo que compreende o período de criação do Sistema Único de Assistência Social (SUAS), em 2004, até 2009, Sitcovsky (2010b) identifica que o Fundo Nacional da Assistência Social saltou de $R \$ 8$ bilhões para $\mathrm{R} \$ 24$ bilhões, e a previsão orçamentária do ano de 2010 para o Ministério do Desenvolvimento Social e Combate à Fome (MDS) foi de quase $\mathrm{R} \$ 39$ bilhões.

Nesse panorama, alguns analistas - Braz (2007), Mota (2011; 2008), Netto (2008), Sitcovsky (2008) - têm apontado que a ofensiva sobre os direitos sociais no Brasil opera-se reconfigurando a seguridade social, inflexionando seu padrão de enfrentamento à questão social, de um lado, com a mercantilização dos serviços sociais, e, de outro, pela centralidade nas ações assistenciais focalizadas e compensatórias, historicamente situadas na esfera da assistência social ${ }^{6}$. Tais pesquisadores utilizam o termo assistencialização para identificar esse processo que ocorre no campo dos direitos sociais no Brasil. Nesse sentido, Mota (2011) referese, sobretudo, ao avanço da mercantilização e da privatização das políticas de saúde e de previdência, concomitante à ampliação da assistência social, que passaria a ser tomada como principal mecanismo da proteção social brasileira. Tais tendências, no entanto, imprimem um desenho particular para a própria assistência social, porquanto sua expansão adquire centralidade através dos programas de transferência de renda. Na formulação de Mota (2011, p. 69): 


\begin{abstract}
AAssistência Social é um direito que pode não se constituir num mito. É um direito que, em determinadas conjunturas, pode se traduzir num mito pela centralidade que vem ocupando como principal meio de enfrentamento da desigualdade. Deste modo, ao ser elevada à condição de principal mecanismo de enfrentamento da desigualdade social, podemos dizer que há uma assistencialização da seguridade social. E tal assertiva não se confunde com o referencial, ou 0 que um dia chamamos de prática assistencialista, mas diz respeito à sua centralidade dentre os mecanismos de proteção vigentes. Numa tradução coloquial, o que acontece é que a Assistência Social, originalmente uma política mediadora e articuladora, parece assumir a condição de política estruturadora. E mais, passa a se constituir numa ideologia que legitima a relação pobreza versus Assistência Social, como passiviza a sociedade.
\end{abstract}

As transformações localizadas na esfera da proteção social, longe de ser despretensiosa, acenam para uma perspectiva de renovação das estratégias de dominação do capital no quadro de acirramento das suas contradições (MOTA, 2011; MOTA; AMARAL; PERUZZO, 2010; SITCOVSKY, 2010a; 2010b). É importante assinalar o papel de destaque que os programas de transferência de renda passam a cumprir no redimensionamento da assistência social, expresso, por exemplo, no impacto que provoca no funcionamento do SUAS e, por conseguinte, na dinâmica das unidades sociais dessa Política. Nesse aspecto, ainda que não possamos esgotar a análise de tal questão, é pertinente a referência aos dados de Stein $(2011$, p. 4):

A experiência brasileira de transferência de renda condicionada não constitui uma ação isolada dos demais países que integram a América Latina, assim como de outras regiões do Planeta. Verificase nos anos recentes uma expansão global da Assistência Social. [...] as novas formas de Assistência Social alcançam, hoje, mais de 150 milhões de famílias pobres nos países em desenvolvimento, com cerca de 750 milhões de beneficiários dos programas [...]. Na América Latina e Caribe, os Programas de transferência de renda estão presentes em 19 países e beneficiam a mais de 25 milhões de famílias, em média de 113 milhões de pessoas, equivalente a $19 \%$ da população da região [...], tais programas vêm assumindo papel central na política de proteção social, direcionados à extrema pobreza. Consideradas as distintas realidades e experiências heterogêneas, eles têm em comum caráter focalizado e condicionado.

É fundamental não subestimar as implicações do (re)direcionamento da política de assistência social na última década, com destaque para seus programas de transferência de renda. De uma parte, os mesmos são capazes de surtir efeitos positivos no processo de reprodução de parcela da força de trabalho desempregada (ou sujeita a condições precárias de trabalho), garantindo-lhe algum acesso ao consumo - e proporcionando a recomposição da superpopulação relativa necessária à ampliação da extração da mais-valia. Por outro lado, são fortemente inscritas no bojo da construção de um projeto e de uma cultura formadora da hegemonia das classes dirigentes.

No contexto de crise e restauração do capital, em que se ampliam a população excedente e a impossibilidade do sistema dominante responder às necessidades de consumo da força de trabalho pela da elevação dos níveis de emprego, a assistência social assume um papel fundamental na reprodução dos trabalhadores supérfluos, que constituem o exército industrial de reserva. Precisamos acrescentar que, embora os programas e benefícios de transferência de renda registrem impactos na diminuição dos índices de pobreza no país, pesquisadores têm indicado que seus custos incidem majoritariamente sobre as rendas do trabalho. Assim, o que se revela não é 
[...] uma transferência de recursos do capital para os trabalhadores, ou, se preferirem, dos ricos para os pobres e, sim, sugere uma redistribuição de renda entre os próprios trabalhadores. (SITCOVSKY, 2008, p. 159).

Portanto, não obstante os ganhos institucionais, legais e regulatórios (e mesmo estruturais, com a ampliação das unidades sociais da assistência) alcançados com a PNAS e a NOB/ $\mathrm{SUAS}^{7}$, os traços fundamentais da assistência social no Brasil são reiterados no novo período, como demonstra o estudo de Boschetti e Salvador (2006, p. 50) apresentando as principais orientações dos programas e ações planejadas pelo governo em 2005:

[...] fortalecimento de benefícios de transferência de renda como BPC e Bolsa-Família; apenas manutenção de ações protetivas e sócio-educativas, com crescimento pífio de recursos que não alçaram mais de $5 \%$ dos recursos do FNAS [...]. Este quadro indica, assim, aumento dos recursos repassados pelo governo federal em forma de transferência de renda diretamente aos beneficiários dos benefícios e manutenção ou pífio crescimento dos recursos destinados a ações que devem ser coletivamente executadas pelos CRAS na modalidade de proteção básica e/ou especial conforme a PNAS e a NOB.

Nesse quadro, a assistência social não configura qualquer ameaça à orientação macroeconômica estabelecida pelos agentes do capital parasitário-financeiro ao Estado brasileiro. Por isso mesmo, tem sido alvo de muitos elogios pelos ideólogos das agências multilaterais ${ }^{8}$, certamente com forte peso na legitimidade e adesão conquistadas pelo governo do Partido dos Trabalhadores.

No que se refere à orientação ideológica assumida, a pedagogia da hegemonia (NEVES, 2005) acionada através dos direitos e políticas sociais no cenário de restauração do capital atenta para a necessidade inexorável de materializar os imperativos econômicos da acumulação - com suas consequências deletérias para as condições de vida das classes subalternas-, sem ameaçar a legitimidade desse modo de produção. A política de assistência social repercute na conformação dos trabalhadores à cultura dominante, constituindo-se instrumento de concertação, através da mistificação que envolve seus conceitos e concepções principais (família, exclusão, vulnerabilidades, situação de risco), as práticas político-pedagógicas utilizadas no trabalho socioassistencial e as estratégias paticipacionistas mobilizadas pelos agentes governamentais.

Podemos evidenciar esquematicamente algumas críticas de que tem sido objeto o texto da PNAS, enquanto um meio pelo qual são difundidos os conceitos e concepções que fornecem uma direção intelectual e moral para a intervenção profissional no campo socioassistencial. No que se refere à centralidade na família, proposta como diretriz da assistência social, Carloto (2006) assinala que, embora sejam apreendidas as determinações históricas na definição de família, permanece a continuidade do enfoque familista e, portanto, de uma centralidade, não apenas na família, mas também na mulher-mãe.

Para Sitcovsky (2008, p. 161), ao contrário do que é propalado na PNAS sobre o estabelecimento de novas bases para a relação entre Estado e sociedade civil,

\section{[...] o que há, na realidade, é um avanço da tentativa de organizar, racionalizar e regulamentar a relação público/privado, com 0 intuito de evitar a sobreposição de ações e 0 desperdício de recursos, sob 0 argumento da eficiência e da eficácia.}

Embora o texto da nova Política reconheça que a gravidade dos problemas sociais brasileiros exige a primazia do Estado na condução da assistência, a chamada sociedade civil é considerada uma parceira na oferta dos serviços, programas, 
projetos e benefícios. Nos termos assumidos, a sociedade civil é compreendida como espaço da colaboração e apresentada como corresponsável pela solução das crescentes contradições sociais, expressas na pobreza, no desemprego, etc. Sitcovsky (2008) afirma que essas parcerias expressam a investida da classe dominante na tentativa de passivizar seus antagonistas, mediante a transferência de responsabilidade na execução das ações socioassistenciais para parte da sociedade civil, notadamente as associações das classes subalternas. Essa convocação da sociedade civil para assumir funções estatais de proteção social é uma evidente orientação presente na agenda neoliberal, no sentido de reduzir os gastos sociais dos governos.

Para Paiva (2006; 2010), as noções exclusão/inclusão, risco e vulnerabilidade social se prestam a recobrir situações concretas da população, sem tornar inteligível seu pertencimento a uma classe social e, portanto, a um tempo e espaço históricos portadores de um projeto político alternativo. A autora nos informa que a conformação histórica da natureza mesma da formação social brasileira revela uma estratégia de hegemonia presente nas respostas fornecidas às expressões da questão social pelas medidas de proteção social (e, em específico, no campo da assistência) que parece ser reiterada: 0 processamento das demandas em geral centralizadas em requerimentos privados, individualizados e com foco prioritário sob o indivíduo vulnerável ou na sua família em risco e não na necessidade social, histórica e coletiva e, menos ainda, no âmbito da luta de classes. As mediações ideológicas e institucionais historicamente acionadas no âmbito da assistência social revelam seu aprisionamento numa esfera residual e periférica, reprodutora de estratégias usuais de mistificação das desigualdades e de ocultamento das suas causas, restringindo a respostas existentes a programas pontuais, pretensamente reformadores das condutas individuais e grupais. Evidenciamse, tradicionalmente, esquemas deletérios de psicologização da questão social, que atribuem aos indivíduos a responsabilidade por sua condição de pobreza, decorrentes de pretensas incapacidades cognitivas, dissimulando as contradições próprias da civilização burguesa.

No campo das estratégias participacionistas, o crescimento da participação da sociedade civil, sobretudo a partir dos anos 1990, se apresenta, para Simionatto e Luza (2011), como repasse das funções do Estado a uma diversidade de organizações através de uma mistificadora pedagogia da solidariedade (ABREU, 2008). É intensificada a assimilação de elementos isolados da sociedade civil (ou de grupos inteiros) para, posteriormente, colocálos a serviço da ordem burguesa, num processo de transformismo e cooptação ao ideário dominante, contribuindo para a restauração do capital mediante consenso ativo dos dominados (ABREU, 2011; SIMIONATTO; LUZA, 2011).

A pesquisa de Abreu (2011) informa que os atuais processos participativo-educativos na assistênciasocialsãoacionadoscomopartedosistema de controle do capital para o enquadramento dos usuários às exigências legais e normas institucionais de acesso aos serviços prestados nos limites restritos e restritivos (focalizados, seletivos e individualizantes) impostos pelo padrão de acumulação às medidas de proteção social. A pedagogia da hegemonia subjacente tende à despolitização e cooptação dos usuários e contribui para a debilitação e inibição de formas de resistência orientada para seus interesses imediatos e históricos, incorporando e subsumindo as demandas participativas e de controle democrático pelas classes subalternas (ABREU, 2011; ABREU; CARDOSO, 2009).

As novas modalidades de participação dos sujeitos nos programas assistenciais assumem, fundamentalmente, duas vias: através das alternativas de trabalho ou outras contrapartidas controladoras (envolvimento produtivo ou cooperação produtiva), supondo, ao mesmo tempo, a adequação e enquadramento das necessidades dos grupos demandantes às condições socioinstitucionais dos atendimentos prestados; e, por meio de estratégias conselhistas na gestão das políticas sociais públicas, 
na qual os conselhos de direitos se constituem enquanto espaços de participação da sociedade civil da gestão pública e no controle social (ABREU, 2008). Para a mesma autora, a reatualização das estratégias participacionistas vincula-se, ainda, à necessidade de administração das lacunas e defasagens presentes no desempenho institucional. A cultura da participação opera reforçando as conotações da autoajuda e da ajuda-mutua, demarcando uma esfera programática da intervenção de agentes profissionais nas relações sociais, na qual a participação popular nos programas governamentais é assumida como eixo central de processos de integração e promoção sociais.

\section{CONCLUSÃO}

Qualquer tentativa de determinar as mediações que conformam as transformações processadas na consolidação da hegemonia burguesa no Brasil - em face da crise estrutural do sistema do capital - demanda uma análise rigorosa da capacidade, historicamente determinada, desse sistema de deslocar suas contradições e antagonismos, através dos mecanismos de controle político e ideológico.

As mudanças estabelecidas no bojo da crise atual, em face dos seus efeitos deletérios sobre a existência humana - e que terminam por ameaçar as próprias relações de hegemonia estabelecidas -, originam-se, fundamentalmente, da necessidade incontornável do capital recompor sua dominação. No interior da dinâmica sócio-reprodutiva imposta, os sistemas de proteção social de caráter focalizado e seletivo, conformados pelahipertrofiados mecanismos assistenciais tradicionalmente localizados no campo da assistência social, são acionados para a atualização da totalidade das relações de forças imprescindíveis à era da servidão financeira. Mas a reprodução da relação-capital é inexoravelmente a reprodução de uma contradição viva. Os mecanismos operados possuem determinados efeitos positivos ainda que crescentemente limitados e problemáticos - sobre as formas de vida das classes subalternas numa época de barbárie social.
Os estudos críticos nos mostram que a assistência social no Brasil opera através de mediações reprodutivo-materiais e ideológicas que corroboram na restauração da dominação burguesa no país, ao contrário de obliterar efetivamente as tendências históricas de acumulação de capital, ou as prerrogativas dos agentes da burguesia parasitáriofinanceira. As transformações institucionais processadas no âmbito dessa Política, cujo destaque se refere à ponderação assumida pelos programas de transferência de renda, vêm orientando a construção e consolidação dos consensos necessários à readequação dos projetos dominantes, ampliando a ação dirigente dos setores burgueses vinculados ao capital financeiro. Ao mesmo tempo, tais mecanismos produzem a própria desorganização política das classes subalternas, neutralizando o desenvolvimento do seu potencial ético-político e a construção mesma de um projeto civilizatório alternativo.

Considerando as disputas hegemônicas em curso, a política de assistência social - nas suas dimensões particulares analisadas anteriormente cumpre um papel passivizador, resultante da própria dinâmica restauracionista atual. As estratégias restauracionistas do capital buscam, através nas modificações das relações de forças, a reatualização da hegemonia burguesa no país, passivizando as classes subalternas, (re)conduzindo-as ao estado econômico-corporativo das forças políticas. Tais estratégias acarretam efeitos imediatos na reprodução da própria superpopulação relativa, ao mesmo tempo em que conduzem a uma reforma intelectual e moral que busca adequar a consciência social das classes aos interesses práticos da burguesia monopolista. Esta última é perfilada pelas ideologias impregnadas nos instrumentos gerenciais e normativos da assistência, e nas práticas políticopedagógicas requeridas para a intervenção dos intelectuais profissionais que atuam no campo socioassistencial.

Essas análises colocam na ordem do dia desafios históricos incontornáveis que 0 tempo presente impõe às organizações e movimentos políticos comprometidos com as lutas contra- 
hegemônicas das classes subalternas. Assinala a necessidade de mobilização para o fortalecimento da disputa ideológica, orientada para desvelar os fundamentos ético-políticos classistas que dinamizam a assistência social na conjuntura brasileira recente. O investimento criação de um movimento histórico dos trabalhadores que supere os processos de passivização em curso deve articular concretamente as lutas parciais e cotidianas numa perspectiva abrangente, que coloque em causa a determinação social estrutural do próprio sistema do capital em sua totalidade. Nesses termos, a assistência social deve ser pensada enquanto mediação econômico-social e ideológica inscrita num projeto civilizatório das classes subalternas, que coloque como horizonte efetivo a superação das contradições e antagonismos constituidores da barbárie social contemporânea.

\section{REFERÊNCIAS}

ABREU, Marina Maciel. Assistência Social, Mobilização e Educação Popular. In: CONSELHO FEDERAL DE SERVIÇO SOCIAL. 0 trabalho do/a Assistente Social no Suas: seminário nacional. Brasília, DF, 2011. p. 229-249.

Serviço Social e a Organização da Cultura: perfis pedagógicos da prática profissional. 2. ed. São Paulo: Cortez, 2008.

; CARDOSO, Franci Gomes. Mobilização social e práticas educativas. In: CONSELHO FEDERAL DE SERVIÇO SOCIAL; ASSOCIAÇÃO BRASILEIRA DE ENSINO E PESQUISA EM SERVIÇO SOCIAL. Serviço Social: direitos sociais e competências profissionais. Brasília, DF, 2009. v.1, p. 593-608.

ALVES, Giovanni. Trabalho e subjetividade: o espírito do toyotismo na era do capitalismo manipulatório. São Paulo: Boitempo, 2011.

. Dimensões da Reestruturação Produtiva: ensaios de sociologia do trabalho. 2. ed. Londrina: Práxis; Bauru: Canal 6, 2007. Disponível em: <http:// www.giovannialves.org/>. Acesso em: 10 jul. 2009.
Trabalho e Mundialização do Capital. 2. ed. Londrina: Práxis, 1999. Disponível em: <http:// www.giovannialves.org/>. Acesso em: 10 jul. 2009.

ANTUNES, Ricardo. Os sentidos do trabalho. 7. ed. São Paulo: Boitempo, 2007.

BEHRING, Elaine Rossetti. Política Social no contexto da crise capitalista In: CONSELHO FEDERAL DE SERVIÇO SOCIAL; ASSOCIAÇÃO BRASILEIRA DE ENSINO E PESQUISA EM SERVIÇO SOCIAL. Serviço Social: direitos sociais e competências profissionais. Brasília, DF, 2009. v.1, p. 301-323.

Políticas Sociais no Governo Lula: uma reПexão. Revista Inscrita, Brasília, DF, ano IV, n. 9, p. 10-14, 2004.

BOSCHETTI, Ivanete. Direito, Trabalho e Riqueza no Brasil: o Conjunto CFESS/CRESS na defesa do Projeto Ético-Político Profissional. In: ENCONTRO NACIONAL CFESS/CRESS, 37., 2009, Brasília, DF. Anais... Brasília, DF, 2009.

BEHRING, Elaine. Política social: fundamentos e história. 2. ed. São Paulo: Cortez, 2007.

; SALVADOR, Evilásio. Orçamento da seguridade social e política econômica: perversa alquimia. Serviço Social e Sociedade, São Paulo, n. 87, p. 25-57, 2006.

BRAGA, Ruy. Apresentação. In: OLIVEIRA, Francisco; BRAGA, Ruy; RIZEK, Cibele. (Orgs.). Hegemonia às avessas, São Paulo: Boitempo, 2010.

A restauração do capital: um estudo sobre a crise contemporânea. São Paulo: Xamã, 1996.

BRASIL. Ministério do Desenvolvimento Social e Combate à Fome. Caderno SUAS, Brasília, DF, 2011. v. V.

BRAZ, Marcelo. OPAC e o Serviço Social: crescimento para quê e para quem? Os setenta anos da profissão e os seus desafios conjunturais. Serviço Social e Sociedade, São Paulo, n. 91, p. 49-61, 2007. 
CARLOTO, Cássia Maria. Gênero, políticas públicas e centralidade na família. Serviço Social e Sociedade, São Paulo, n. 86, p. 139-155, 2006.

COGGIOLA, Osvaldo. Fome, capitalismo e programas sociais compensatórios: histórico e análise comparada da experiência brasileira. [S. I.: s. n.], 2009. Mimeo.

COUTINHO, Carlos Nelson. A hegemonia da pequena política. In: OLIVEIRA, Francisco; BRAGA, Ruy; RIZEK, Cibele (Orgs.). Hegemonia às avessas. São Paulo: Boitempo, 2010. p. 29-48.

DURIGUETTO, Maria Lúcia. Sociedade civil e democracia: um debate necessário. São Paulo: Cortez, 2007.

FERNANDES, Nalu. Presidente do banco mundial elogia o Bolsa Família. Portal de notícias do Estado de São Paulo, São Paulo, 2009. Disponível em: $<$ http://www.estadao.com.br>. Acesso em: 20 jun. 2012.

GRAMSCI,Antônio. Cadernos do cárcere: introdução ao estudo da filosofia e a filosofia de Benedetto Croce. Tradução de Carlos Nelson Coutinho com a colaboração de Luiz Sergio Henriques e Marco Aurélio Nogueira. 5. ed. Rio de Janeiro: Civilização Brasileira, 2011. v. 1.

Cadernos do cárcere: notas sobre o Estado e a Política. Tradução de Carlos Nelson Coutinho com a colaboração de Luiz Sergio Henriques e Marco Aurélio Nogueira. Rio de Janeiro: Civilização Brasileira, 2007. v. 3.

HARVEY, David. Condição pós-moderna: uma pesquisa sobre as origens da mudança cultural. São Paulo: Loyola, 1993.

IAMAMOTO, Marilda. Serviço Social em tempo de capital fetiche: capital financeiro, trabalho e questão social. São Paulo: Cortez, 2010.

KAMEYAMA, Nobuco. Trajetória da produção de conhecimento em Serviço Social: avanços e tendências (1975-1997). Cadernos ABESS, São Paulo, n. 8, p. 33-76, 1998.
KOSIK, Karel. Dialética do concreto. Rio de Janeiro: Paz e Terra, 1976.

MANDEL, Ernest. 0 capitalismo tardio. São Paulo: Nova Cultura, 1985.

MARQUES, Rosa Maria. 0 regime de acumulação sobre a dominância financeira e a nova ordem no Brasil. In: MARQUES, Rosa Maria; FERREIRA, Mariana Ribeiro Jansen (Orgs.). O Brasil sob a nova ordem: a economia brasileira contemporânea - uma análise dos governos Collor e Lula. São Paulo: Saraiva, 2010. p. 1-19.

MÉSZÁROS, István. Para além do capital: rumo a uma teoria da transição. Tradução de Paulo Cezar Castanheira e Sergio Lessa. São Paulo: Boitempo, 2009.

MOTA, Ana Elizabete. Assistência Social em Debate: Direito ou Assistencialização? In: CONSELHO FEDERAL DE SERVICO SOCIAL. 0 trabalho do/a Assistente Social no Suas: Seminário Nacional. Brasília, DF, 2011. p. 65-71.

A centralidade da Assistência Social na Seguridade Social nos anos 2000. In: MOTA, Ana Elizabete (Org.). 0 Mito da Assistência Social. São Paulo: Cortez, 2008. p. 133-147.

; AMARAL, Angela Santana do; PERUZZO, Juliane Felix. $O$ novo desenvolvimentismo e as políticas sociais na América Latina. In: MOTA, Ana Elizabete (Org.). As ideologias da contrarreforma e o Serviço Social. Recife: Ed. UFPE, 2010. p. 153178.

NETTO, José Paulo. [Palestra]. In: ENCONTRO NACIONAL DE PESQUISADORES EM SERVIÇO SOCIAL, 11., 2008, São Luís. Anais... São Luís: ABEPSS, 2008.

\section{Capitalismo monopolista e Serviço}

Social. 5. ed. São Paulo, 2006.

A conjuntura brasileira: o Serviço Social posto à prova. Serviço Social e Sociedade, São Paulo, n. 79, p 5-26, 2004a. 
Notas sobre a reestruturação do Estado e a emergência de novas formas de participação da sociedade civil. In: BOSCHETTI, Ivanete (Org.). Política Social: alternativas ao neoliberalismo. Brasília, DF: UnB, 2004b. p. 61-84.

Crise do Socialismo e Ofensiva Neoliberal. 2. ed. São Paulo: Cortez, 1995.

NEVES, Maria Lúcia W. (Org.) A nova Pedagogia da Hegemonia: estratégias do capital para educar o consenso. São Paulo: Xamã, 2005.

OLIVEIRA, Francisco de. Hegemonia às avessas. In: __ ; BRAGA, Ruy; RIZEK, Cibele (Orgs.). Hegemonia às avessas, São Paulo: Boitempo, 2010. p. 21-28.

[Palestra]. In: ENCONTRO NACIONAL DE PESQUISADORES EM SERVIÇO SOCIAL, 11., 2008, São Luís. Anais... São Luís: ABEPSS, 2008.

PAIVA, Beatriz Augusto et al. Participação popular e Assistência Social: contraditória dimensão de um especial direito. Revista. Katályzis, Florianópolis, v. 13, n. 2. p. 250-259, 2010.

O SUAS e os direitos socioassistenciais: a universalização da seguridade social em debate. Serviço Social e Sociedade, São Paulo, n. 87, p.524, 2006.

SILVEIRA Jr., Adilson Aquino. A Assistência Social no Brasil - o estado da arte. In: ENCONTRO NACIONAL DE PESQUISADORES EM SERVIÇO SOCIAL, 12., 2010, Rio de Janeiro. Anais... Rio de Janeiro: ABEPSS, 2010.

A Assistência Social entre a afirmação e a negação de uma lógica perversa: 0 estado da arte nas revistas de Serviço Social \& Sociedade nos anos 1990. In: ENCONTRO NACIONAL DE PESQUISADORES EM SERVIÇO SOCIAL, 11., 2008, São Luís. Anais... São Luís: ABEPSS, 2008.

SIMIONATTO, Ivete; LUZA, Edinaura. Estado e sociedade civil em tempos de contra-reformas: lógica perversa para as políticas sociais. Textos e Contextos, Porto Alegre, v. 10, n. 2. p. 215-226, 2011.
SITCOVSKY, Marcelo. Bolsa família e reprodução da força de trabalho no Brasil: implicações sócioeconômicas e políticas. 2010a. 222 f. Tese (Doutorado em Serviço Social) - Centro de Ciências Sociais Aplicadas, Universidade Federal de Pernambuco, Recife, 2010.

Conciliações e contradições entre assistência social e trabalho: 0 impacto do Bolsa Família. In: MOTA, Ana Elizabete. As ideologias da contrarreforma e o Serviço Social. Recife: Ed. UFPE, 2010b. p. 211-242.

Particularidades da expansão da Assistência Social no Brasil. In: MOTA, Ana Elizabete (Org.). 0 Mito da Assistência Social. São Paulo: Cortez, 2008. p. 147-179.

STEIN, Rosa Helena. Programas de transferência de renda: o que revelam e o que escondem. Politizando: Boletim do Núcleo de Estudos e Pesquisas em Política Social, Brasília, DF, n. 8, p. 4-5, 2011.

\section{NOTAS}

${ }^{1}$ Ver o levantamento e análise realizada por lamamoto (2010) e por Kameyama (1998). Para uma apreciação de menor abrangência - mas igualmente significava - ver Silveira Jr. (2008; 2010).

${ }^{2} \mathrm{Na}$ palestra de abertura proferida em dezembro de 2008, no XI Encontro Nacional de Pesquisadores em Serviço Social, José Paulo Netto apresentou uma exposição sobre as problemáticas que perpassam a pesquisa em Serviço Social. Um panorama das produções na área é oferecido por lamamoto (2010).

${ }^{3}$ É preciso sinalizar que temos como plano de fundo do pacto fordista/keynesiano o fenômeno do quase pleno emprego, possibilitado pela fase histórica de ascensão do capital nesse periodo.

${ }^{4}$ Estamos considerando a assistência social sempre em sua concreticidade histórica. Sabemos que a mesma constitui um campo de disputas entre as classes, e sua conformação é determinada historicamente na correlação das forças em presença. A política social não pode ser compreendida com uma conformação estática, mas em sua configuração mutável, dinamizada pelas lutas de classes nas formações sociais especificas.

${ }^{5}$ É preciso ponderar aqui, por outro lado, que essa hegemonia consiste num equilíbrio instável (GRAMSCl, 2007) 
dinamizado por uma variedade de forças políticas diferentes e antagonistas. 0 que sinaliza para uma heterogeneidade e complexidade desse processo hegemônico, com suas disputas internas e resistências.

${ }^{6} 0$ redimensionamento dessa Política se expressa também na ampla adesão dos municípios brasileiros aos parâmetros institucionais e operativos do SUAS, a partir das exigências da própria regulamentação vigente. Os dados do MDS (BRASIL, 2011) apontam que $99,5 \%$ dos municípios brasileiros haviam aderido ao SUAS em 2011.

7 Respectivamente, Política Nacional de Assistência Social, de 2004 e Norma Operacional Básica do Sistema Único de Assistência Social, de 2005.

${ }^{8}$ Como demonstra matéria de Fernandes (2009) no jornal Estadão, Presidente do banco mundial elogia o Bolsa Família.

\section{Adilson Aquino Silveira Júnior}

Assistente Social

Doutorando em Serviço Social da Universidade Federal de Pernambuco (UFPE)

E-mail: j_r1987@hotmail.com

\section{Simone Sousa Leite}

Assistente Social

Mestra em Serviço Social da Universidade Federal de Pernambuco (UFPE)

Professora de Serviço Social da Autarquia Educacional de Serra Talhada (AESET)

E-mail: simoneazuos@gmail.com

Universidade Federal de Pernambuco - UFPE

Av. Prof. Morais Rego, 1235 - Cidade Universitária, Recife - PE CEP: 50670-901

Autarquia Educacional de Serra Talhada - AESET

Av. Afonso Magalhães - Centro - PE 